ORIGINAL ARTICLE

\title{
Ability of obstacle crossing is not associated with falls in independent ambulatory patients with spinal cord injury
}

\author{
S Amatachaya ${ }^{1,2}$, W Pramodhyakul ${ }^{1,2}$, P Wattanapan ${ }^{2,3}$ and W Eungpinichpong ${ }^{1,4}$
}

Study design: A 6-month prospective design.

Objective: To investigate the relationship between ability of obstacle crossing and falls in independent ambulatory participants with spinal cord injury (SCI).

Setting: A tertiary rehabilitation center.

Methods: Ninety-four participants were evaluated for their $\mathrm{SCl}$ characteristics, ability of walking over small obstacles and functional ability relating to dynamic balance control, lower-extremity motor strength (LEMS) and walking ability. Their fall data were then prospectively monitored every month for 6 months.

Results: Twenty-four participants failed in obstacle crossing. However, only eight of the thirty-three participants who fell during the follow-up period were unable to clear the obstacle while walking. The LEMS and functional ability of the participants who failed were significantly poorer than those of individuals who passed an obstacle-crossing test $(P \leqslant 0.001)$. For the falls, significant differences between the groups were found only in age and tactile scores. The findings further indicated that failures on obstacle crossing were not significantly associated with falls $(P>0.05)$.

Conclusion: Ability of obstacle crossing in a closed/controlled environment clearly correlated with intrinsic causes, whereas a fall in an open environment may be associated with not only intrinsic but also extrinsic causes. Therefore, apart from functional ability, rehabilitation professionals may need to consider extrinsic factors around falls in order to manage risk of injury to the patients.

Spinal Cord (2015) 53, 598-603; doi:10.1038/sc.2015.22; published online 10 February 2015

\section{INTRODUCTION}

Approximately $50-95 \%$ of patients with incomplete spinal cord injury can regain ambulatory functions by the time of discharge. ${ }^{1}$ However, the sensorimotor deterioration following spinal cord injury (SCI) likely reduces their ability to modify movements according to the task demands. Therefore, these patients encounter a high risk of falls and subsequent injuries (39-75\% of the patients fell during 5-12 months), and most falls occur during walking, frequently due to tripping over an obstacle. ${ }^{1-6}$

Currently, there is only little evidence on obstacle crossing in patients with SCI. Amatachaya et al. ${ }^{7}$ found that $44 \%$ of independent ambulatory participants with SCI $(n=34)$ failed to walk over small obstacles. The researchers suggest that gait safety of the participants may be threatened and they may encounter a high risk of injury after discharge. Nevertheless, the cross-sectional investigation without gathering fall data might not be able to confirm the relationship between failures on obstacle crossing and falls of these individuals. The present study explored information relating to the ability of obstacle crossing and falls, and their association in independent ambulatory participants with SCI. The researchers hypothesized that a large proportion of independent ambulatory participants with SCI had difficulty in walking over small obstacles, and thus they had a high risk of falls. The researchers further hypothesized that failures on obstacle crossing and falls were associated with poor sensorimotor scores and functional ability.

\section{MATERIALS AND METHODS \\ Participants}

This study was a 6-month prospective design in independent ambulatory participants with SCI, aged at least 18 years, from a tertiary rehabilitation center in Thailand. From sample size calculation for multiple logistic analysis, the study required 94 participants. The eligible participants had an American Spinal Injury Association impairment scale (AIS) $\mathrm{C}$ or $\mathrm{D}$, and ability of independent walking with or without a walking device for at least $15 \mathrm{~m}$ (Functional Independent Measurement Locomotor scores $\geqslant 5$ ). The exclusion criteria were having an SCI from progressive diseases, and any signs or symptoms that might affect balance and ambulatory ability, such as pain in the musculoskeletal system with an intensity of pain more than 5 out of 10 on a numeric rating pain scale, deformity of the spine and lower extremities, and visual deficits. Participants provided written informed consent approved by the Khon Kaen University ethics committee in human research before participation in the study.

\section{Apparatus}

The study required a 10-m walkway and six wooden obstacles (each of them was $60 \mathrm{~cm}$ long and $0.8 \mathrm{~cm}$ thick) of different sizes, including $1 \mathrm{~cm}$ wide, $4 \mathrm{~cm}$ wide, $8 \mathrm{~cm}$ wide, $1 \mathrm{~cm}$ high, $4 \mathrm{~cm}$ high and $8 \mathrm{~cm}$ high (Figure 1a), in order to represent the sizes of obstacles likely found in homes and communities. ${ }^{7-9}$

${ }^{1}$ School of Physical Therapy, Faculty of Associated Medical Sciences, Khon Kaen University, Khon Kaen, Thailand; ${ }^{2}$ Improvement of Physical Performance and Quality of Life (IPQ) Research Group, Khon Kaen University, Khon Kaen, Thailand; ${ }^{3}$ Institute of Medicine, Suranaree University of Technology, Nakhon Ratchasima, Thailand and ${ }^{4}$ Research Center in Back, Neck, Other Joint Pain and Human Performance (BNOJPH), Khon Kaen University, Khon Kaen, Thailand

Correspondence: Professor S Amatachaya, School of Physical Therapy, Faculty of Associated Medical Sciences, Khon Kaen University, Khon Kaen 40002 Thailand. E-mail: samata@kku.ac.th

Received 31 October 2014; revised 26 December 2014; accepted 14 January 2015; published online 10 February 2015 
a

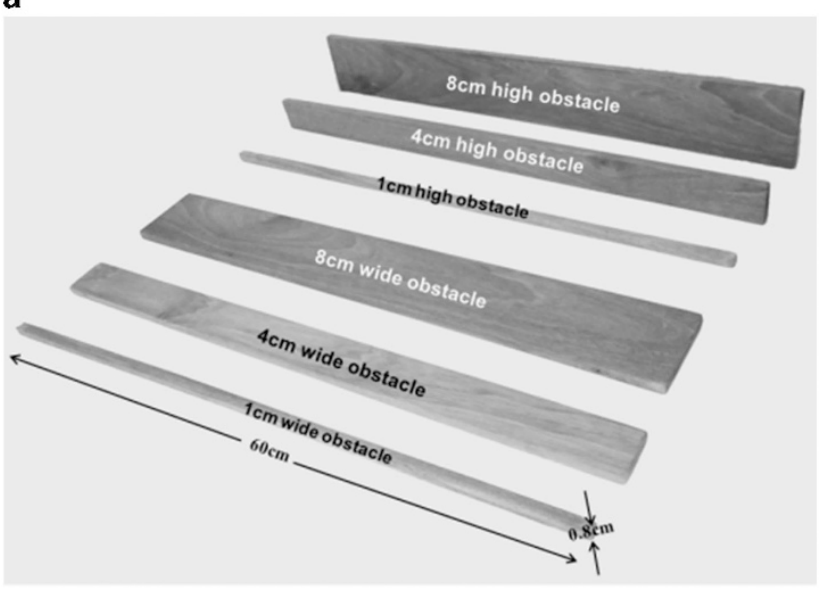

b

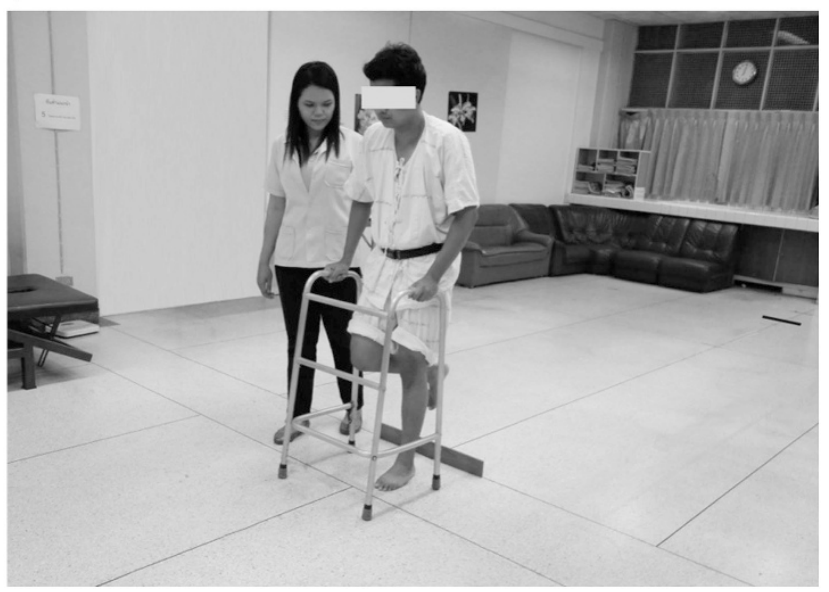

Figure 1 Obstacle used and testing protocol. (a) Wooden obstacles (each of them $60 \mathrm{~cm}$ long and $0.8 \mathrm{~cm}$ thick) of six sizes, including $1 \mathrm{~cm}$ wide, $4 \mathrm{~cm}$ wide, $8 \mathrm{~cm}$ wide, $1 \mathrm{~cm}$ high, $4 \mathrm{~cm}$ high and $8 \mathrm{~cm}$ high. (b) An obstaclecrossing test (the figure presents 'pass on an $8-\mathrm{cm}$-high obstacle').

\section{Research protocol}

The eligible participants were interviewed and assessed for their demographics and SCI characteristics. On the following day, the participants were evaluated for their ability of obstacle crossing, and for functional ability relating to the ability of obstacle crossing and risk of fall using the Timed Up and Go Test (TUGT), Five Times Sit-to-Stand Test (FTSST) and 10-Meter Walk Test (10MWT). Details of the tests are as follows.

Obstacle-crossing tests. Participants were assessed for their ability to walk over an obstacle of six sizes (one trial per size, six trials in total) in a sequence to balanced random allocation among the participants (Figure 1b). Before the tests, a wide obstacle was placed flat on the floor and a high obstacle was attached vertically to the floor using a small amount of adhesive gum. Thus, if any obstacle was contacted by a foot or walking device, it fell flat on the floor to minimize any risk of injury or tripping to the participants. The participants were instructed to not attempt any obstacles that might pose a risk of injury to them. Outcomes of the tests were recorded as 'pass' or 'fail'. A 'pass' referred to the ability to successfully walk over an obstacle with both limbs and a walking device without any physical assistance. A 'fail' was recorded when the participants required assistance from the tester, or contacted the obstacle with a limb or walking device. ${ }^{7-9}$

Functional ability tests

Timed up and go test. The test assesses dynamic balance control while performing basic mobility tasks (such as changing from sitting to standing, walking and turning around), in which the time used to complete the test is strongly related to levels of functional mobility, balance and postural control, walking ability and the risk of falls. ${ }^{10-12}$ Participants stood up from an armrest chair, walked around a traffic cone that was located $3 \mathrm{~m}$ from the chair and returned to sit down on the chair at their fastest and safest speed. The average time required over the three trials was recorded. $5,6,11,12$

Five times sit-to-stand test. The test is sensitive and responsive to assess lower-extremity motor strength (LEMS), sensorimotor integration and balance control. ${ }^{13,14}$ Participants were instructed to stand up with the hips and knees in full extension, and sit down five times at their fastest and safest speed. The average time used over the three trials was recorded. ${ }^{11-14}$

Ten-meter walk test. The 10MWT reflects walking speed that is associated with motor function, walking endurance and overall quality of gait. ${ }^{11,12,15}$ Participants walked at a self-selected speed along a $10-\mathrm{m}$ walkway, and the average time required over the middle $4 \mathrm{~m}$ of the walkway was recorded to minimize acceleration and deceleration effects. ${ }^{11,12}$

During the tests, participants fastened a lightweight safety belt around their waist with an assessor always walking or being beside the participants to ensure their safety, as well as accuracy of the tests. They were able to use a walking device and take a period of rest between the tests and the trials as required.

After completing the tests, participants received a fall diary sheet ${ }^{5,6}$ to make a daily record of the fall data at home. The researcher (WP) telephoned the participants every month for 6 months to ask about the fall data. A fall was defined as an unplanned or unexpected event that occurred during the performance of an activity while standing or walking, or changing postures, and resulted in a person coming into contact with the ground or other lower supporting surface. ${ }^{2-6}$

\section{Statistical analyses}

Descriptive statistics were applied to explain demographics of the participants and findings of the study. As the data were not normally distributed, the findings between the groups (that is, pass and fail on obstacle crossing, or fallers or non-fallers) were compared using the Mann-Whitney $U$-test for continuous data and the $X^{2}$-test for categorical data. Stepwise multiple logistic regression analysis was applied to determine the effects of independent variables on the outcome observed. The results were reported in terms of an adjusted odds ratio (aOR) with corresponding 95\% confidence intervals (95\% CI) and Beta $(\beta)$ coefficients with the s.e. around the Beta coefficient. The aOR provides information about the increase or decrease in the possibility of the dependent variable (failures on obstacle crossing or fall), given that the independent variable has occurred when controlling for other independent variables in the model (being a risk or protective factor). The Beta coefficients represent the log of the aOR or the influence of independent variables on the dependent variable. ${ }^{16} \mathrm{~A}$ level of statistical significance was set at $P$-value $<0.05$.

\section{RESULTS}

Ninety-four participants completed the study (Figure 2). Most of them were male $(n=62)$ and at a chronic stage of SCI (Table 1$)$. Fifty participants walked with a walking device, including a standard walker $(n=40)$, axillary crutches $(n=5)$, a multilegged cane $(n=3)$ and a single cane $(n=8)$. The data on ability of obstacle crossing and falls are as follows.

\section{Obstacle crossing}

Twenty-four participants (26\%) failed to walk over an obstacle (Figure 2): 15 participants failed in more than one trial (range 2-6 trials), and nine participants had a problem in only one trial while walking over a rather large obstacle $(4$ or $8 \mathrm{~cm})$. The total number of failures was 64 trials (59 trials occurred due to foot contact and 5 trials because of walking device contact, Figure 3). Nearly half of the participants who failed had AIS C and all of them walked with a standard walker (Table 1). Their functional ability as measured using the TUGT, FTSST and 10MWT and their lower-extremity motor 
96 independent ambulatory patients with SCI agreed to participate in the study

2 patients were lost during the follow-up period due to changing their telephone numbers
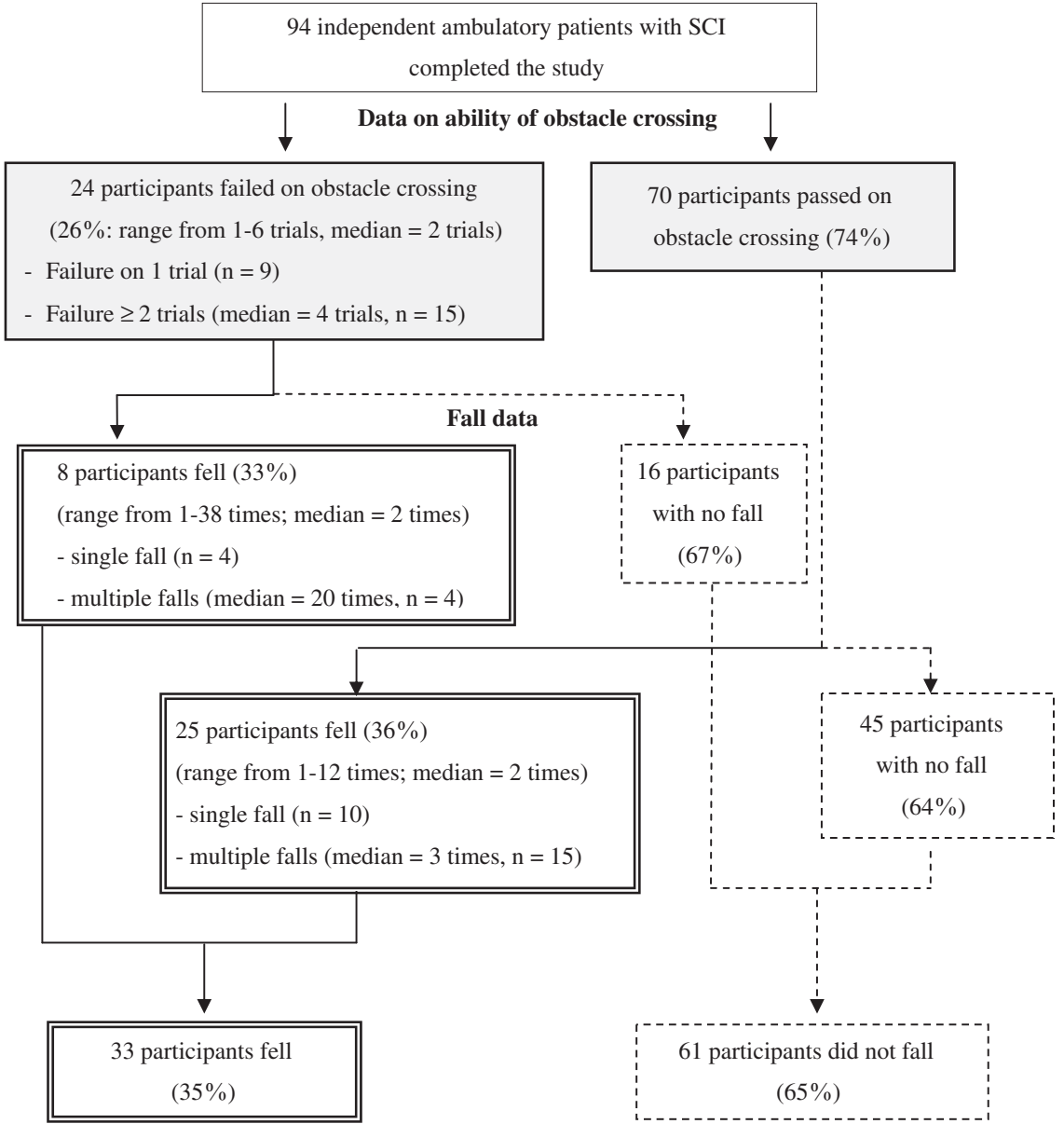

Figure 2 Participation flow chart, and the data on obstacle crossing and falls of the participants.

Table 1 Demographics, $\mathrm{SCl}$ characteristics and functional ability of the participants

\begin{tabular}{|c|c|c|c|c|c|c|c|}
\hline \multirow[t]{2}{*}{ Variable } & \multirow[t]{2}{*}{ Total $(n=94)$} & \multicolumn{2}{|c|}{ Obstacle-crossing ability } & \multirow[t]{2}{*}{ P-value } & \multicolumn{2}{|c|}{ Fall } & \multirow[t]{2}{*}{ P-value } \\
\hline & & Pass $(\mathrm{n}=70)$ & Fail $(\mathrm{n}=24)$ & & Fall $(\mathrm{n}=33)$ & Non-fall $(\mathrm{n}=61)$ & \\
\hline Age (years) ${ }^{a}$ & $53.5(42.0: 62.0)$ & $53(42.3: 61.8)$ & $58.0(41.3: 67.5)$ & 0.276 & $46.0(33.0: 54.0)$ & $58.0(48.0: 63.0)$ & 0.001 \\
\hline Post-injury time (months) ${ }^{a}$ & $36(14.0: 60.0)$ & $28(14.0: 60.0)$ & $45.00(14.3: 73.0)$ & 0.440 & $40.0(23.0: 60.0)$ & $24.0(11.0: 72.0)$ & 0.272 \\
\hline Sex: male/female $(n)^{\mathrm{b}}$ & $62 / 32$ & $50 / 20$ & $12 / 12$ & 0.056 & $22 / 11$ & $40 / 21$ & 0.915 \\
\hline Cause: non-traumatic/traumatic $(n)^{\mathrm{b}}$ & $68 / 26$ & $50 / 20$ & $18 / 6$ & 0.736 & $21 / 12$ & $47 / 14$ & 0.165 \\
\hline Stage of injury: chronic/subacute $(n)^{\mathrm{b}}$ & $74 / 20$ & $56 / 14$ & $18 / 6$ & 0.606 & $29 / 4$ & $45 / 16$ & 0.124 \\
\hline Severity of $\mathrm{SCl}$ : AIS C/D $(n)^{\mathrm{b}}$ & $15 / 79$ & $4 / 66$ & $11 / 13$ & $<0.001$ & $8 / 25$ & $7 / 54$ & 0.107 \\
\hline \multicolumn{8}{|l|}{ Level of $\mathrm{SCl}$} \\
\hline Incomplete tetraplegia/incomplete paraplegia ${ }^{\mathrm{c}}(n)^{\mathrm{b}}$ & $26 / 68$ & $16 / 54$ & $10 / 14$ & 0.075 & $9 / 24$ & $17 / 44$ & 0.951 \\
\hline Walking device used: yes/no $(n)^{\mathrm{b}}$ & $56 / 38$ & $32 / 38$ & $24 / 0$ & $<0.001$ & $17(52)$ & $39(64)$ & 0.242 \\
\hline Timed Up and Go Test (s) ${ }^{a}$ & $19.6(11.8: 41.9)$ & $14.6(10.3: 30.1)$ & $46.9(38.8: 55.9)$ & $<0.001$ & $14.5(10.2: 41.2)$ & $26.3(12.5: 47.7)$ & 0.105 \\
\hline Five Times Sit-to-Stand Test (s) & $13.6(10.2: 18.5)$ & $12.8(9.1: 15.9)$ & $19.0(13.5: 20.7)$ & 0.001 & $11.9(8.5: 16.4)$ & $14.5(11.2: 19.0)$ & 0.066 \\
\hline Ten-Meter Walk Test $\left(\mathrm{ms}^{-1}\right)^{\mathrm{a}}$ & $0.6(0.2: 0.8)$ & $0.7(0.3: 0.9)$ & $0.2(0.2: 0.2)$ & $<0.001$ & $0.7(0.2: 0.9)$ & $0.5(0.2: 0.8)$ & 0.364 \\
\hline
\end{tabular}

Abbreviations: AIS, American Spinal Injury Association (ASIA) Impairment Scale; SCI, spinal cord injury.

${ }^{a}$ The data are presented using the median (interquartile range: Q1-Q3). The data between the groups were compared using the Mann-Whitney U-test.

bThe data between the groups were compared using the $X^{2}$-test.

cParticipants with incomplete tetraplegia had a level of the lesion from C5 to C7, and those with incomplete paraplegia had a level of lesion from T4 to L3. 
Failures on a wide obstacle

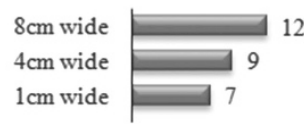

Failures on a high obstacle

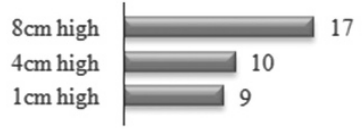

Causes of failures

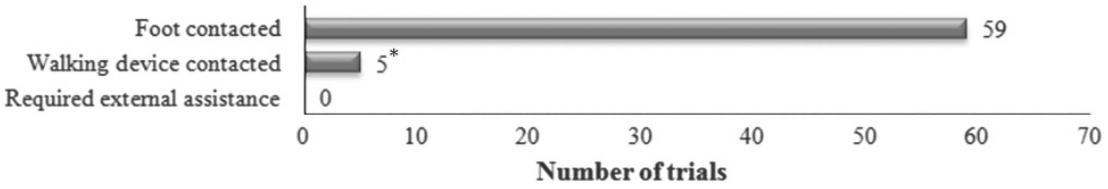

Figure 3 Data relating to failure on obstacle crossing. Note: 24 participants failed in obstacle crossing (range from 1 to 6 trials per participant), and the total number of failures was 64 trials. *Two trials from participants with incomplete paraplegia and three trials from those with incomplete tetraplegia.

Table 2 Sensorimotor scores of the participants

\begin{tabular}{|c|c|c|c|c|c|c|c|}
\hline \multirow[t]{2}{*}{ Variable } & & \multicolumn{2}{|c|}{ Obstacle-crossing ability } & \multirow[t]{2}{*}{ P-value } & \multicolumn{2}{|c|}{ Fall } & \multirow[t]{2}{*}{ P-value } \\
\hline & & Pass $(n=70)$ & Fail $(n=24)$ & & Yes $(n=34)$ & No $(n=60)$ & \\
\hline (scores) & LEs (50 scores) & $40.56 \pm 8.742$ & $31.67 \pm 11.746$ & $<0.001$ & $37.88 \pm 11.449$ & $38.52 \pm 9.677$ & 0.776 \\
\hline Tactile & UEs (32 scores) & $31.26 \pm 2.913$ & $30.08 \pm 4.736$ & 0.155 & $30.82 \pm 3.688$ & $31.03 \pm 3.385$ & 0.780 \\
\hline (scores) & LEs (36 scores) & $24.91 \pm 6.469$ & $25.04 \pm 7.220$ & 0.936 & $23.06 \pm 5.559$ & $26.02 \pm 6.983$ & 0.037 \\
\hline
\end{tabular}

Abbreviations: LE, lower extremity; UE, upper extremity.

The data are presented using mean \pm s.d., $P$-value from the Mann-Whitney $U$-test.

Table 3 Factors associated with failures on obstacle crossing in independent ambulatory participants with $\mathrm{SCl}$

\begin{tabular}{|c|c|c|c|c|c|c|c|}
\hline Variable ${ }^{a}$ & $\begin{array}{c}\text { Total } \\
(\mathrm{n}=94)\end{array}$ & $\begin{array}{l}\text { Participants who passed } \\
\qquad(\mathrm{n}=70)\end{array}$ & $\begin{array}{l}\text { Participants who failed } \\
\qquad(\mathrm{n}=24)\end{array}$ & $\beta$ coefficient & s.e. & aOR $(95 \% \mathrm{Cl})$ & $\mathrm{P}$ \\
\hline Age: $<60$ years & 64 & $50(78)$ & $14(22)$ & -0.07 & 0.75 & $0.93(0.21-4.05)$ & 0.921 \\
\hline Cause of SCl: non-traumatic & 68 & $50(74)$ & $18(26)$ & -0.19 & 0.82 & $0.82(0.16-4.11)$ & 0.812 \\
\hline Stage of injury: chronic & 73 & $55(75)$ & $18(25)$ & -0.71 & 0.82 & $0.49(0.09-2.46)$ & 0.388 \\
\hline Severity of SCI: AIS C & 15 & $4(27)$ & $11(73)$ & 2.81 & 0.89 & $16.59(2.90-94.81)$ & 0.002 \\
\hline
\end{tabular}

Abbreviations: AIS, American Spinal Injury Association (ASIA) impairment Scale; aOR, adjusted odds ratio; 95\% Cl, 95\% confidence interval; SCI, spinal cord injury.

aThe variables are categorized as follows: age: $\geqslant 60$ years (reference group)/ $<60$ years; sex: female (reference group)/male; cause of SCI: traumatic (reference group)/non-traumatic; stage of injury: acute (reference group)/chronic; severity of SCI: AIS D (reference group)/AIS C; level of injury: incomplete tetraplegia (reference group)/incomplete paraplegia; using a walking device: no (reference group)/yes.

bThe data are presented using number (\%).

scores were significantly lower than those of participants who passed an obstacle-crossing test $(P \leqslant 0.001$, Tables 1 and 2$)$. Factors significantly associated with the ability of obstacle crossing included sex, severity of SCI and the requirement of a walking device $(P<0.05$, Table 3$)$.

\section{Falls}

Thirty-three participants (35\%) experienced at least one fall during 6 months (range 1-38 times per participant and the total number of falls $=150$ times, Figure 2). The falls occurred mostly while walking within the house and their workplaces frequently because of stumbling over an obstacle, followed by lower-limb muscle weakness and loss of balance (Table 4). However, only eight of these participants failed in the obstacle-crossing test (Figure 2). Participants who fell were significantly younger and had significantly poorer tactile scores of the lower extremities than those who did not fall $(P<0.05$, Tables 1 and 2). Apart from age, the multiple logistic regression analysis indicated no significant factors associated with falls, including failures on obstacle crossing $(P>0.05$, Table 5$)$. 


\section{DISCUSSION}

To successfully walk over an obstacle, the participants needed to modify their movements to conform with the sizes of obstacles on the floor, that is, use a flexor strategy to increase foot clearance (for a high obstacle) or lengthen a step (for a wide obstacle), on a small base of support during a single limb stance period. The task poses high demands on balance control, LEMS and walking ability. ${ }^{7-9}$ Therefore, the study used the TUGT, FTSST and 10MWT, which had been verified for their applicability in ambulatory individuals with SCI, to

\section{Table 4 Fall data of the participants}

\begin{tabular}{lc}
\hline Variable & Number of falls (\%) \\
\hline Period of falls & $69(46)$ \\
Morning & $50(34)$ \\
Afternoon & $20(13)$ \\
Evening & $11(7)$ \\
Night & \\
Location of falls & \\
Within the house & $52(35)$ \\
Workplace & $43(28)$ \\
Immediate surroundings of the house & $36(24)$ \\
Community & $19(13)$ \\
Activity during falls & \\
Walking & $133(88)$ \\
Changing posture & $16(11)$ \\
Standing & $1(1)$ \\
Causes of falls as perceived by the participants & $98(6)$ \\
Stumble over an obstacle & \\
Lower limb muscle weakness & \\
Loss of balance & \\
Other reasons & \\
Reduced mobility and social participation & \\
Muscular tear or pain & \\
\hline
\end{tabular}

aThe total number of falls was 150 .

bLess attention, slippery floor, dizziness and rapid movements. reflect these abilities of the participants. ${ }^{10-17}$ The findings indicate the importance of intrinsic factors or internal causes (that is, the impairments of sensorimotor functions, balance control and walking ability) for ability of obstacle crossing, in which the data of the TUGT, FTSST, 10MWT and lower-extremity motor scores of the participants who failed were significantly poorer than those who could clear an obstacle while walking $(P \leqslant 0.001$, Tables 1 and 2$)$.

The findings further indicated that being male, having incomplete paraplegia, AIS C and walking with a walking device were significantly associated with failures on obstacle crossing (Table 3). Although male patients may have less natural neurological recovery because they tended to have more lesion severity than female patients, for a given level and completeness of the lesion, male patients tend to have better functionality. ${ }^{18}$ Having incomplete paraplegia infers greater intact portions as compared with those with incomplete tetraplegia and good supportive function of the upper extremities. Thus, these characteristics were the protective factors for failures on obstacle crossing $(\mathrm{aOR}=0.15$ and 0.14 for being male and having paraplegia, respectively, Table 3). In contrast, having AIS $\mathrm{C}$ meant severe sensorimotor impairments that limited the ability of the participants to modify movements according to the task demands. ${ }^{19}$ Thus, having AIS C increased the possibility of failures on obstacle crossing 16.59fold over those who had AIS D $(P<0.005$, Table 3$)$. Walking devices are commonly prescribed in order to compensate for lower-extremity muscle weakness, impaired balance control and poor walking ability to promote levels of independence using contribution from the upper extremities. ${ }^{11,12}$ Having these characteristics may infer individuals with difficulty to control their body balance and modify movements of the lower extremities according to the dimensions of the obstacle on the floor. Therefore, a large proportion of participants who used a walking device failed to walk over an obstacle due to foot or device contact with the obstacle (Figure 3).

For the falls, the findings were in agreement with previous studies $^{1,20}$ in that participants who fell were significantly younger than those who did not fall $(P=0.001$, Table 1$)$; however, their functional ability showed no significant differences. Younger participants might be more active and have a greater level of energy and enthusiasm compared with older individuals. However, the impairments of the tactile scores $(P<0.05$, Table 2$)$ might affect the ability of the participants to control their movements and body balance. ${ }^{1}$ Thus, they had increased exposure to fall opportunities. However, the nonsignificant differences of functional ability between the groups

Table 5 Factor associated with falls in independent ambulatory participants with SCI

\begin{tabular}{|c|c|c|c|c|c|c|c|}
\hline Variable $e^{\mathrm{a}}$ & $\begin{array}{c}\text { Total } \\
(\mathrm{n}=94)\end{array}$ & $\begin{array}{l}\text { Participants with } \\
\text { no falp }(\mathrm{n}=60)\end{array}$ & $\begin{array}{c}\text { Participants who } \\
\text { felp }(n=34)\end{array}$ & $\beta$ coefficient & s.e. & $\operatorname{aOR}(95 \% \mathrm{Cl})$ & $\mathrm{P}$ \\
\hline Age: $<60$ years & 64 & $36(56)$ & $28(44)$ & 1.19 & 0.59 & $3.29(1.04-10.39)$ & 0.042 \\
\hline Sex: males & 62 & $40(65)$ & $22(35)$ & -0.83 & 0.55 & $0.44(0.15-1.29)$ & 0.136 \\
\hline Cause of SCl: non-traumatic & 68 & $46(68)$ & $22(32)$ & -0.40 & 0.54 & $0.66(0.23-1.91)$ & 0.453 \\
\hline Stage of injury: chronic & 73 & $44(60)$ & $29(40)$ & 0.78 & 0.61 & $2.18(0.66-7.17)$ & 0.200 \\
\hline Severity of SCl: AIS C & 15 & $7(47)$ & $8(53)$ & 1.56 & 0.79 & $4.74(1.01-22.32)$ & 0.049 \\
\hline Level of injury: incomplete paraplegia & 68 & $44(65)$ & $24(35)$ & -0.33 & 0.55 & $0.72(0.25-2.10)$ & 0.548 \\
\hline Using a walking device: yes & 56 & $38(68)$ & $18(32)$ & -0.39 & 0.55 & $0.67(0.23-1.99)$ & 0.476 \\
\hline Failure on obstacle crossing: yes & 24 & $16(67)$ & $8(33)$ & -0.77 & 0.77 & $0.46(0.10-2.09)$ & 0.317 \\
\hline
\end{tabular}

Abbreviations: AIS, American Spinal Injury Association (ASIA) impairment Scale; aOR, adjusted odds ratio; 95\% Cl, 95\% confidence interval; SCI, spinal cord injury.

aThe variables are categorized as follows: age: $>60$ years (reference group)/ $<60$ years; sex: female (reference group)/male; cause of SCl: traumatic (reference group)/non-traumatic; stage of injury: acute (reference group)/chronic; severity of SCI: AIS D (reference group)/AIS C; level of injury: incomplete tetraplegia (reference group)/incomplete paraplegia; using a walking device: no (reference group)/yes; fall: no (reference group)/yes.

The data are presented using number $(\%)$ 
may reflect the influence of not only intrinsic but also extrinsic factors or external causes on fall risk of the participants., ${ }^{2,3,5-7}$

Although the falls occurred mostly due to stumbling over an obstacle, failures on obstacle crossing showed no significant correlation to the fall data (Table 5). The findings may be associated with conditions of the obstacle-crossing tests and the actual environments when the participants fell after discharge. The obstacle-crossing tests were carried out in a predictable, uncluttered and controlled environment of a rehabilitation room in which the distraction was at a minimum. The participants were also aware of the positions and sizes of the obstacles on the floor. In contrast, walking in an actual environment is more complex, and sometimes the participants performed a dual-task while walking, such as thinking of something, singing or talking to others, that distracted their attention from walking. Thus, failures on obstacle crossing showed no significant correlation to falls of the participants.

The findings may imply that the improvement of functional ability and motor strength could promote the ability of obstacle crossing of the participants in a closed environment. However, to reduce the risk of falls, rehabilitation professionals may need to consider both intrinsic and extrinsic causes, and the incorporation of an open and complex environment into the rehabilitation practice is vital for fall management. Nevertheless, some limitations may affect data interpretation. First, the study included participants with a wide range of functional ability at both subacute and chronic stages of SCI in order to clearly represent factors associated with failure on obstacle crossing (Table 3). However, participants at a subacute stage of injury had high potential for functional recovery during the follow-up period for fall data and this may affect the findings for fall risk of the participants. Second, the sensorimotor deterioration was assessed on the basis of the standard neurological classification of SCI ${ }^{19}$ which did not include data on proprioception. Third, the fall data did not consider single and multiple falls separately, as the data of previous reports ${ }^{1,20}$ revealed that the number of falls did not significantly correlate to the functional ability of individuals with SCI. Fourth, the ability of obstacle crossing was measured using small obstacles because they are frequently found in homes and communities ${ }^{7-9}$ and to avoid an unacceptable risk of injury to the participants. On the other hand, the findings may imply that the problems would be exacerbated when the participants encounter a larger obstacle after discharge. Last, the multiple logistic regression analysis did not provide the odds ratio for the requirement of a walking device because all participants (100\%) who failed used a walking device. In fact, the basic assumption in analyzing the data is that $5 \%$ but no more than $95 \%$ of the participants should have that condition (walking with or without a walking device). ${ }^{16}$ To improve the explanatory power of the findings, this variable needs 281 participants. Therefore, a further study that includes more number of participants with the assessment of proprioceptive sensation and the incorporation of dual-task paradigms or actual environments may better explain the correlation between the ability of obstacle crossing and falls.

\section{DATA ARCHIVING}

There were no data to deposit.

\section{CONFLICT OF INTEREST}

The authors declare no conflict of interest.

\section{ACKNOWLEDGEMENTS}

The study was supported by funding from the Improvement of Physical Performance and Quality of Life (IPQ) research group, Faculty of Associated Medical Science and the Khon Kaen University, Khon Kaen, Thailand. The researchers sincerely thank Ms Kittiyawadee Srisim for her help in data analysis and Mr Ian Thomas for his help in preparing the manuscript.

1 Wirz M, Muller R, Bastiaenen C. Falls in persons with spinal cord injury: validity and reliability of the Berg Balance Scale. Neurorehabil Neural Repair 2010; 24 70-77.

2 Brotherton SS, Krause JS, Nietert PJ. Falls in individuals with incomplete spinal cord injury. Spinal Cord 2007; 45: 37-40.

3 Wannapakhe J, Arayawichanon P, Saengsuwan J, Amatachaya S. Changes of functional ability in patients with spinal cord injury with and without falls during 6 months after discharge. Phys Ther 2014; 94: 675-681.

4 Amatachaya S, Wannapakhe J, Arrayawichanon P, Siritarathiwat W, Wattanapun P. Functional abilities, incidences of complications and falls of patients with spinal cord injury 6 months after discharge. Spinal Cord 2011; 49: 520-524.

5 Phonthee S, Saengsuwan J, Siritaratiwat W, Amatachaya S. Incidence and factors associated with falls in independent ambulatory individuals with spinal cord injury: a 6-month prospective study. Phys Ther 2013; 93: 1061-1072.

6 Phonthee S, Saengsuwan J, Amatachaya S. Falls in independent ambulatory patients with spinal cord injury: incidence, associated factors and levels of ability. Spinal Cord 2013; 51: 365-368.

7 Amatachaya S, Thaweewannakij T, Adirek-udomrat J, Siritaratiwat W. Factors related to obstacle crossing in independent ambulatory patients with spinal cord injury. J Spinal Cord Med 2010; 33: 144-149.

8 Said C, Goldie P, Patla A, Sparrow W. Effect of stroke on step characteristics of obstacle crossing. Arch Phys Med Rehabil 2001; 82: 1712-1719.

9 Amatachaya S, Pramodhyakul W, Srisim K. Failures on obstacle crossing in independent ambulatory patients with spinal cord injury and associated factors. Arch Phys Med Rehabil 2015; 96: 43-48.

10 Podsiadlo D, Richardson S. The timed 'Up \& Go': a test of basic functional mobility for frail elderly persons. J Am Geriatr Soc 1991; 39: 142-148.

11 Poncumhak P, Saengsuwan J, Kamruecha W, Amatachaya S. Reliability and validity of three functional tests in ambulatory patients with spinal cord injury. Spinal Cord 2012; 51: 214-217.

12 Saensook W, Poncumhak P, Saengsuwan J, Mato L, Kamruecha W, Amatachaya S. Discriminative ability of the 3 functional tests in independent ambulatory patients with spinal cord injury who walked with and without ambulatory assistive devices. J Spinal Cord Med 2014; 37: 212-217.

13 Whitney SL, Wrisley DM, Marchetti GF, Gee MA, Redfern MS, Furman JM. Clinical measurement of sit-to-stand performance in people with balance disorders: validity of data for the Five-Times-Sit-to-Stand Test. Phys Ther 2005; 85: 1034-1045.

14 Kaewjoho C, Mato L, Amatachaya S. Relationship between the Sit-to-Stand test and lower extremity muscle strength in ambulatory patients with spinal cord injury. J Med Tech Phys Ther 2014; 26 (in press, in Thai).

15 Jackson AB, Carnel CT, Ditunno JF, Read MS, Boninger ML, Schmeler MR et al. Outcome measures for gait and ambulation in the spinal cord injury population. J Spinal Cord Med 2008; 31: 487-499.

16 van Hedel HJ, Wirz M, Dietz V. Assessing walking ability in subjects with spinal cord injury: validity and reliability of 3 walking tests. Arch Phys Med Rehabil 2005; 86: 190-1966.

17 Plichta SB, Garzon LS. Statistics for Nursing and Allied Health. Lippincott Williams \& Wilkins: Philadelphia, PA, USA, 2009.

18 Sipski ML, Jackson AB, Gomez-Marin O, Estores I, Stein A. Effects of gender on neurologic and functional recovery after spinal cord injury. Arch Phys Med Rehabil 2004; 85: 1826-1836

19 Maynard FM, Bracken MB, Creasey G, Ditunno JF, Donovan WH, Ducker TB et al. International standards for neurological and functional classification of spinal cord injury. Spinal Cord 1997; 35: 266-274.

20 Srisim K, Saengsuwan J, Amatachaya S. Functional assessments for predicting a risk of multiple falls in independent ambulatory patients with spinal cord injury. J Spinal Cord Med. (e-pub ahead of print 21 January 2014). 